2018 Global Marketing Conference at Tokyo Proceedings: 1564-1577 (July 2018) https://doi.org/10.15444/GMC2018.13.07.03

\title{
RETHINKING THE RETAIL MIX? THE IMPACT OF CHINESE GLOBETROTTERS ON EUROPEAN LUXURY SHOPS
}

\author{
Tiziano VESCOVI, Ca' Foscari University of Venice, Italy ${ }^{1}$ \\ Charlotte PELLIZZARI, Ca' Foscari University of Venice, Italy
}

\begin{abstract}
Purpose: as they travel more, the Chinese consumers are making a rapidly-growing share of their luxury purchases outside the Mainland. Their purchases are now the most part of the sales in the luxury shops in Europe. This paper aims to analyze if and how their buying behavior is affecting the retail mix.

Design approach: in order to analyze the influence of Chinese customers on European luxury shops a qualitative research has been developed by mean of 346 observations, in a period of four months, of the buying behavior inside a luxury shop in Italy. We used the mystery sales person approach. The research aimed to verify the consistency of the traditional retail mix of a luxury shop with the requests of these new customers.
\end{abstract}

Findings: the research highlighted that the buying behavior of the Chinese globetrotters is quite different compared to the traditional European and American luxury customers, and that their requests are not fitting with the existing luxury shop retail mix.

Research limitation: The research process was heavily limited by the particular situation of a Chinese luxury customer, who doesn't like to be interviewed. So the research approach should be totally indirect, similar to a mystery research. Only one luxury brand could be included in the sample, while a comparison between more brands seems to be more fruitful.

Practical implications: the traditional retail mix of luxury shops, based on long and careful relationship, exclusive spaces and atmospheres, timeless and experiential experiences inside the point of sales are not fitting with the needs of Chinese luxury shoppers. It must be reconsidered and innovate, coping with the paradox represented by traditional European customer desires and new Chinese ones: the same location for two totally different approaches.

Originality: in the new era of globalization almost the totality of the previous studies analyzes the strategy of western retail luxury chains in China, focusing on how the West is influencing Chinese customers, skipping the reverse situation. This paper focuses how Chinese customers can influence European luxury shops.

Keywords: retailing mix, consumer behavior, luxury products, Chinese consumers

\footnotetext{
${ }^{1}$ tiziano.vescovi@unive.it
} 


\section{INTRODUCTION: CROSS BORDER SHOPPERS' BEHAVIOR AND RETAIL STRATEGIES}

For years, luxury shoppers have been considered a sort of global segment, acting in the same way in different cultures and places. As a matter of fact, luxury flagship stores are almost the same for a brand all over the world, following consistently the brand image strategy, the brand/store experience, the customer care service. This paper wants to highlight that things are changing, due to the great wave of Chinese luxury tourists.

Many studies have been made in consumer behavior when the shopper is out of his/her normal shopping area, some of those focus on cross border travels. In this article two main paths of study should be identified in order to analyze the salient literature consistently with the aim of this study, the first more general, the second more specific: a) shopping trips and consumer behavior; b) cross border luxury shopping. How the travelling shoppers affect the retail strategy? This aspect has being pointed out mainly considering the assortment of the store and in general very few studies afford the question in luxury shopping.

Despite the weakened global economy, the market for luxury goods continues to demonstrate huge potential growth, especially with Chinese consumer market. The demand for luxury goods in China continues to increase, driven by a number of positive factors such as the growing number of affluent and middle class, rising household disposable income and higher luxury spending, women affirmation and business leaders as well as the increasing number of people traveling.

In buying luxury products Chinese buyers are more differentiated and unique, ranging from experienced consumers with a high degree of sophistication to luxury novices. In addition, Chinese consumers are the most generous (Chen and Kim 2013), allocating about $50 \%$ of their spending on luxury gifts (against a global average of $40 \%)$.

By 2012, the acceleration of Chinese buying overseas resulted in a $60 \%$ of total expenses (Roland Berger 2014). Chinese have then become the first nationality of luxury spending. Given the developed infrastructures, the increased urbanization and a growing portion of the population in China becoming wealthier, there has been the emergence of a new class of luxury buyers (Wang et al. 2011).

China continues to play a fundamental role for global luxury brands. As consumers travel at an increasing rate, their tastes and knowledge of products continues to widen. It is therefore increasingly important for luxury players to maintain a strong brand image and synergies in their marketing and product selection both in China and overseas.

Chinese consumers also make a selective reasoning among countries and associate to each one specific products. Easily guessing, Switzerland comes top for luxury watches, France for cosmetics, Italy for clothes and leather goods, while Germany for the automotive industry. This phenomenon is increasing in the Chinese mentality, since it represents a direct link with the product itself and the corresponding heritage 
associated. Heritage is, indeed, one of the strongest value added to a product, since it embodies the craftsmanship and history carried out along time.

As they travel more, indeed, the Chinese are making a rapidly-growing share of their luxury purchases outside the Mainland, in 2015 10\% more compared to 2014 (Bain \& Co. 2016). Much of this overseas shopping takes place in Hong Kong and Macau, but Europe is growing in appeal among Chinese luxury consumers. That is more than double the European share two years ago. According to China Tourism Research Institute, China had 127 million outbound visitors in 2017 and they spent 126 billion US dollars, increases of 4\% and 5\% compared with 2016. Among overseas travelers, nearly 1 out of 4 reported that they bought a luxury good while traveling, expressing positive feelings. The first five, out of ten, destinations where in East Asia, while the sixth and the seventh were France and Italy, as the first European destinations. Looking closely to the Italian situation, according with ENIT (Italian National Agency for Tourism), in 2016 3,785,000 Chinese tourists visited Italy, since visas are valid for the whole Schengen area.

If the number of Chinese traveling abroad for personal reasons has increased ten times more in ten years, according to the 2016 report of National Bureau of statistics of China, the use of the Web has helped to inquire them about brands and prices of their favorite European products. According to the declaration made by the managers of several luxury brands, in the main tourist destination cities in France and Italy, more than $70 \%$ of the retail stores sales can be attributed to Chinese overseas tourists. In Italy the average shop ticket for each person was 874 euros in 2015, in Milan 1,208 euros. Therefore, the buying behavior of the Chinese globetrotters concerning luxury products is an important phenomenon that should be studied in order to understand if their wants and expectations are fitting with the traditional retail mix strategies of the European luxury retail stores.

\section{LITERATURE REVIEW}

Marketing literature about travelling shoppers is mainly focused on the consumer behavior in two different situations, shopping trips and outshopping or cross border shopping.

Shopping trips have been analyzed both from a logistic point of view (Susilo et al 2013), and from a behavioral point of view (Gilbride et al 2015) considering planned and unplanned purchases, convenience influence (Reimers and Chao 2014), shopping for themselves versus shopping for someone else (Gillison and Reynolds 2016), but mainly within the same nation, so the trip should be considered or an adding cost in the buying behavior or an adding effort in search of better conditions as convenience prices, larger assortments, or better service.

Outshoppers literally go extra miles to outshop for better quality and assortment of merchandise, higher quality of personal service, more pleasant shopping atmospherics, and more competitive prices (Guo and Wang 2009). Retail stores play a central role in attracting tourists to engage in cross-border shopping. Wong and Lam (2016) propose a framework of relationships leading from cross-border shopping motives to store outcomes and destination outcomes through the mediating roles of store loyalty program benefits and store shopping satisfaction. Many studies concern the border 
between USA and Mexico (Hernandez and Vicdan 2014; Baruca and Zolfagharian 2013; Sullivan et al. 2012; Guo et al. 2006) and in general common borders as Malaysia and Singapore (Piron 2001), Barain and Saudi Arabia (Yavas and AbdulGarder 1991), The Netherland and Germany (Spierings and van der Velde 2013), South East Europe (Dmitrovic and Vina 2007), Hong Kong and China (Wang 2004). All these studies consider the cross-border shopping phenomenon both from a convenience and a cultural perspective. However, been the common border an "easy" border, the cultural distance was minimal and the long trip conditions are not been focused so much. From an economic perspective the tax differences (Leal et al. 2010) are considered as main reason for cross boarding shopping, however this is not the angle of this work. Very few studies focused long distance shopping trips and cultural strong diversity as can be the case of Chinese travelling shoppers in west Europe. Wang et al. (2010) investigate Chinese consumers' international outshopping motives from a culture perspective based on Hofstede's five cultural dimensions while Yong et al. (2010) focus on a mix of cultural and convenience reasons. All the studies focus the consumer behavior, even ethnocentrism (Piron 2002), patriotism and terror (Guo and Wang 2009), but not the consequences for the retail mix strategy in deep.

Concerning in particular luxury cross border purchases, studies focuses on tourism and shopping. Park et al. (2010) analyze the importance of the shopping venues and destination for luxury shopping connecting them to luxury buying behavior. Tourism shopping patterns for luxury products are identify in the case of Dubai destination (Zaidan 2016) and Singapore (Henderson et al. 2011), as well as different cultures, Western Asian and Hispanic, are compared as tourist shopping behavior (Park and Reisinger 2009). However the main goal of these studies are to analyze destinations' characteristics and attraction strength and patterns of consumer behavior. The focus on destinations forces to consider mainly typical shopping destinations as Dubai or other similar, more than normal touristic or business cities, i.e. destinations where retail strategy is planned only for tourists and not for both tourist and residents. Some studies focus the importance of the store location, being flagship store, in luxury branding. Arrigo (2015) considers six worldwide capitals in order to generate a luxury sense of place, while Manlow and Nobbs (2013) compare NYC and Paris Louis Vuitton flagship stores, considering both the consumers' and management's perception. Several studies concern Chinese consumer behavior in luxury purchases, analyzing culture and luxury consumptions (Li and Wong 1998, Guoxin et al 2011), brand equity and face saving (Siu et 1. 2016). Regarding in particular the cross border shopping behavior of Chinese consumers, Choi et al. (2016) apply the Schwarz model to Chinese shopping tourists, identifying the shopping travel characteristics of Chinese tourist, focusing on how to achieve tourist satisfaction. Bian and Forsythe (2011) compared Chinese and US purchase intention for luxury brands, but not in travel situation. Zhan and He (2012) analyzed the luxury consumption in China, but they not consider different behaviors of inland and outland shoppers. Anyway none of the studies focuses on how the Chinese shoppers affect the retail mix strategy.

In summary, despite many studies are carried out concerning shopping trips and cross border shopping, very few consider the implication in luxury retail marketing mix when the buyers have a distant culture and a very different purchase approach as the Chinese shoppers. Being Europe, mainly Italy and France, a luxury shopping destination for Chinese tourists, this study aims to identify how the big wave of Chinese luxury shoppers is affecting the luxury retail strategies. 
Exhibit 1. Literature review: number of articles for each research path.

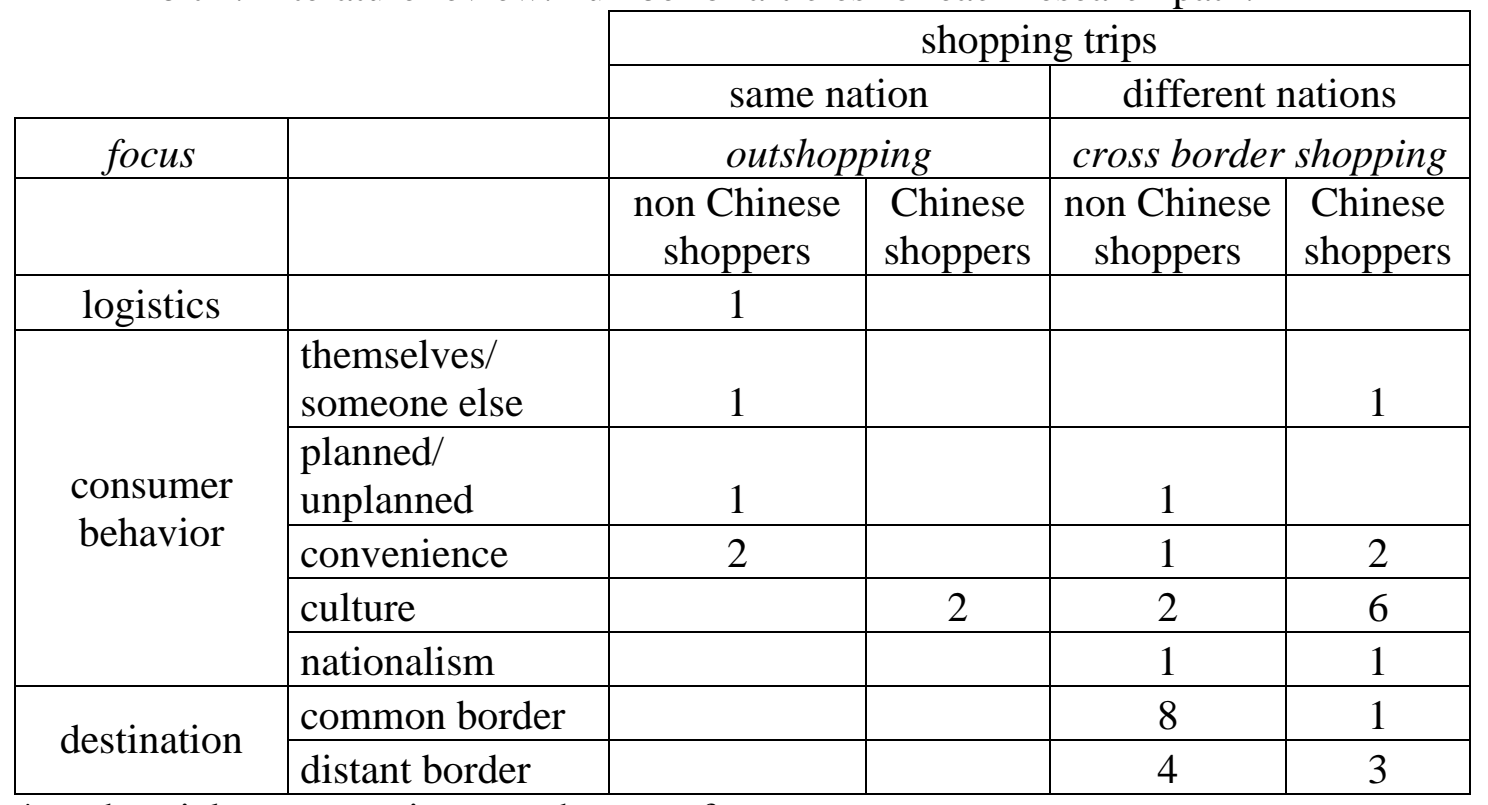

* each article can contain more than one focus

\section{REASONS TO BUY ABROAD FOR A CHINESE GLOBETROTTER}

There are several reasons that exhort Chinese luxury consumers to have their expenditures outside their home country, being economical, cultural and social. Here below are listed the motives that prompt them toward this choice.

\section{The price discrepancy}

The price discrepancy between luxury products sold in China and overseas is one the main drivers of economic advantage that encourages wealthy Chinese wealthy consumers to shop outside their Mainland. Based on data estimated by the Chinese Ministry of Commerce, the average price of luxury goods in China is $45 \%$ higher than Hong Kong, 51\% higher than in the United States, and 72\%33 higher than in France.

\section{The increase in personal wealth}

Beyond the price gap, there are many other reasons for which Chinese are more willing to do they luxury expenditures abroad. Reading a report made by Credit Suisse of 2011, the wealth per capita has increase three times from 2009 to 2011, and by 2016 is will continue to grow and arrive at least to more than a double figure. According to these previsions, it becomes easier to understand that with a greater income, the will of traveling abroad is definitely more concrete and feasible.

\section{The Limited Production Selection}

Luxury products are not delivered in the same quantities and collections everywhere. One basic reason why Chinese are more apt to travel for buying is that often there is a limited product selection, imposed by government and brands, on what they receive in their Home Country. On the brands' side, there is an intentional will of limiting the relative offer in China, as it is due to different materials and goods import policies. More than that, mainly basic items are found in the Chinese market, where limited edition and special edition are only sold in the main European shopping hubs. 


\section{The Importance of The Country of Origin}

Chinese consumers are aware and know that having a luxury product where it has been crafted and sewed adds prestige and honor per se. They are even aware that, even if identical in China, buying abroad adds value, based on counterfeiting product reasons. Even though they are not well-educated consumers, they can understand the meaning of Made in Italy or Made in France, and pomp it towards friends and families. Shopping in countries where products are effectively made, increase the preciousness of the product itself, since many Chinese consumers, either for economic reasons or working constraints, do not have so much time to travel to Europe.

\section{The Gift Tradition}

Social gifting is particularly entrenched in Chinese culture; those having the chance of traveling are used to buy always presents for their relatives, friends or business partners, as considered a must for them having had the chance of being in Europe or in the United States.

In particular, gifting actions take much more relevance when associated with festivity period, such as Christmas or Spring Festival. In these occasions, even luxury brand create specific products targeted for this group of consumers, which are sold just in a limited number of countries, in order to preserve a degree of exclusivity. According to Bain \& Company report of 2012, even if the major purpose of gifting is to provide friends and relatives with a own image of travel possibility and economic availability.

\section{The Authenticity of The Products}

Since China's worldwide reputation on handcrafted products is often, if not always, associated to counterfeits of luxury products, Chinese are more apt to make their purchases where they are $100 \%$ sure that what they are choosing is genuine. Since Chinese consumers are extremely aware of their counterfeit culture, they have become more conscious of quality of products than their counterparts elsewhere in the world. They are much more aware of the difference between an authentic bag and a fake one. For this reason Chinese luxury consumers buy a large percentage of their luxury goods while traveling abroad.

\section{THE RESEARCH}

In order to analyze how the impact of Chinese globetrotters growing wave on European luxury shops a qualitative research was made in 2016. The research questions have been considered in the research were the following:

H1: Chinese globetrotter luxury shopper act in different ways when they buy luxury product in Europe compare to typical luxury customers.

$\mathrm{H} 2$ : their shopping behavior is not fitting with the traditional retail mix strategy of a luxury flagship store.

Despite the huge literature on luxury products, luxury purchase motivations, luxury brand strategies, etc. very few studies were made on the luxury retail service and the luxury client expectations (Tisovski 2014, Amatulli and Guido 2011). Luxury shops are quite different compare the rest of retail outlets, because of the client expectations, the customer service, the atmosphere, the experience, etc. but seems that the literature consider these characteristics as done, maybe because of the traditional and 
consolidated approach. So the retail mix of a luxury store is expected as being characterized by high customer service, luxury atmosphere, relatively long time permanence, customization, and privacy. We tried to verify if these traditional believes are still consistent with the new Chinese globetrotter luxury consumers. Because of the particular nature of luxury stores, was not possible to make any interview to the customers. Actually the store managers, following the indication of the headquarters, do not permit any action that can disturb the customers while buying. The luxury shopper does not like to be asked about his/her purchase and any personal question can affect the relationship between the customer decreasing the brand image. Inside the flagship store, any customer is in a personal kingdom.

So, according with the store management, the research methodology we adopt was the observation of the behaviors followed by Chinese shoppers. In doing this, without affecting directly any brand-customer relationship, we used the mystery shopper method (Wilson 2001; van der Wiele et al. 2005; Minghetti and Celotto 2014). Obviously in this case this was modified by two researchers in two different approaches: i) a mystery shopper role, entering the store twice a week, in different days and different opening hours, staying in the store for at least one hour observing the behavior of Chinese customers; ii) a mystery salesperson role, acting as a salesperson for four months, serving Chinese customers with the help of a Chinese speaking salesperson. Obviously the mystery salesperson was working daily part-time in the flagship store. Both the researchers used a common behavioral survey form collecting the main characteristics of the target, the product preferences, the kind of shopping list, the shopping interaction language, the COO perception, the way the taxes should be refund, and the consequences of the time deadline, as summarized in exhibit 4.

The luxury flagship store we chose for the research was the Christian Dior shop, the location was Venice. Christian Dior was chosen because is a globally known luxury French brand having a great number of products in its lines made in Italy. So the country of origin of the brand in many cases is different from the country of origin of the products, even if the both are European. In Dior's case we would analyze the country of origin perception in a complex context, French, Italian, European, from a Chinese point of perception. Moreover, buying a French brand in Italy the consumer is making an interesting shortcut between European goods perception. While the European and American customer have a clear image of the two country of origin, France and Italy, from a Far-East point of view this can be not so clear and distinct. We wanted to check the country of origin culturally and geographical distant perception (Godey et al. 2013), melting in a less precise concept, but nevertheless correct, as "European" (Vescovi et al 2013).

Venice-Italy was chosen as location because is one of the most visited cities of Italy by tourists (more than 8 millions of tourists in 2014, for 34 millions nights). Venice is also the second most visited Italian city by Chinese tourists ( $87 \%$ of tours made by Chinese tourists include Venice), and people from China represent the ethnicity more involved in luxury purchases in Venice. The period of observation started in December 2015, ending in Mid-April 2016.

Within this time the Chinese consumers behavior was directly observed, how it is related to luxury goods shopping purchase, while the sales personnel was constrained 
to tailor the shopping experience directly to meet their preferences. The observation was done during all the days of the week, weekend included, in the afternoon (being the most used time to shop by the target). Just avoiding to disturb the buying behavior within a luxury store, no questionnaire was submitted or interview done (also the language and cultural barriers were considered). Nevertheless, as well as the observation of the behaviors, two questions were addressed to all the Chinese customers:

- Why do you buy in Italy instead than in China?

- Do you know that the product is made in Italy?

Exhibit 2. Data from in-store observations

\begin{tabular}{|c|c|c|}
\hline factor & description & $\begin{array}{l}\text { numbe } \\
r\end{array}$ \\
\hline target & $\begin{array}{l}\text { high class } \\
\text { medium-high } \\
\text { class }\end{array}$ & $\begin{array}{l}184 \\
162\end{array}$ \\
\hline $\begin{array}{l}\text { product } \\
\text { preferences }\end{array}$ & $\begin{array}{l}\text { logo } \\
\text { Non-sober } \\
\text { sober }\end{array}$ & $\begin{array}{l}171 \\
104 \\
71\end{array}$ \\
\hline shopping list & $\begin{array}{l}\text { list } \\
\text { photos } \\
\text { none }\end{array}$ & $\begin{array}{l}140 \\
129 \\
77\end{array}$ \\
\hline $\begin{array}{l}\text { shopping } \\
\text { interaction }\end{array}$ & $\begin{array}{l}\text { English } \\
\text { Chinese }\end{array}$ & $\begin{array}{l}54 \\
292\end{array}$ \\
\hline COO perception & $\begin{array}{l}\text { French } \\
\text { Italian } \\
\text { European }\end{array}$ & $\begin{array}{l}98 \\
87 \\
161 \\
\end{array}$ \\
\hline tax refund & $\begin{array}{l}\text { mainland } \\
\text { Hong Kong }\end{array}$ & $\begin{array}{l}195 \\
151\end{array}$ \\
\hline time deadline & $\begin{array}{l}\text { drop off } \\
\text { quick buying } \\
\text { no limits }\end{array}$ & $\begin{array}{l}96 \\
118 \\
132\end{array}$ \\
\hline
\end{tabular}

total observations 346

Every time a group of Chinese clients or even a unit (single person or more frequently two-three persons) left the shop, the research form was filled, in order to keep memory of the consumer behavior. In total 346 observations were considered in the research. Some of those (118) were really brief, due to the time available for the shopping activities that should be carried out in the meantime, but anyway they were sufficient to be included in the research, the others where long enough to be collected in all the aspects deeply.

The data collected by the observations are described in exhibit 4 .

Out of the numbers included in exhibit 4, each researcher collected more qualitative records concerning the behavior of the shoppers within the store. All the qualitative 
descriptions where compared and discussed, every three weeks, in order to define common findings that could be used in the qualitative description of the behaviors. Our main observations can be summed up in the following points.

a) Targets - the Chinese consumers interested in luxury goods are extremely heterogeneous: there are consumers belonging to very high social classes, as well as some from medium-high ones. The latter are though the main focus for luxury brands in the current years, since they are expanding their level of wealth and they are moving towards more Western lifestyle.

b) Product preferences - Their attention is mainly aimed towards everything that might show the brand logo, opting for bright colors and gold details rather than any other choice of more sober versions. It can be stated that the consumers rely much more on the overall brand country-of-origin effect rather than the specific technical features, the manufacturing techniques and the country where the products are made. On the other hand in the most of the cases they come into the store with information already acquired through the web, nevertheless they are quite persuadable towards other products. Usually they come with the photos of what they are looking for, being either a direct choice or requests sent by friends or relatives.

More than that, what most attracts their attention are the products advertised in their country, mainly between stars and celebrities (which is currently an actress and singer named Angelababy), having these a very strong influence on their choice. Jointly, the same attitude occurs for all those products targeted specifically for their country. An example can be given by the monkey bracelet, sold in January, to celebrate the Chinese New Year.

c) Shopping interactions - Conducting a sale with a Chinese consumer is not easy, because very often they look for someone who is able to communicate in their own language. In fact, even though several of them have studied English language, their knowledge is widespread but limited. For this reason, Dior as well as almost every flagship store of this segment relies on at least one native speaker sales associate. As the data found confirm, Venice is one of the most important poles of attraction for Chinese consumers, where there are many visiting groups. Extremely importance then has the time that Chinese groups have available for their shopping tours. As it has been previously analyzed, the majority of Chinese consumers travel abroad through organized group tours, where the excursions and sightseeing appointments are planned precisely to be stuck in the whole day. That's why the time factor is another important element to be taken into consideration, since it can often represent a barrier to achieve a final sale. Another interesting aspect is that Chinese consumers often do not have a clear idea about the brand country-of-origin. Indeed, many times a misunderstanding occurs between the latter and the country where the products are practically made.

d) Other incentives - Another element of great relevance is the reliance on the Tax Free refund. According to a report published by Global Blue on March 2014, Chinese are the first nationality among the top 10 spenders, they spend abroad over three times they spend locally (Bain 2014). They have accounted for the $34 \%$ of the world tax free refund in 2015, since for $82 \%$ shopping represents a vital part of their traveling experience. Christian Dior has fixed the tax free refund at the $12 \%$, resulting in a 
consistent amount of saving portion. They provide the consumers with the avoidance of the duty payment, since the products are shipped directly to relatives or friends living in Hong Kong. With the Chinese passport, then, Chinese can fly to Hong Kong and retire their own wares.

e) Time line - being the most of time travelling in group, the Chinese shoppers have a limited amount of time to spend in the store and a severe deadline. It means that several times every purchase have been made in a frantic situation, and several time they should drop off their purchases and leave the point of sales. Therefore, time management become a strategic issue.

\section{DISCUSSION}

The evidences from the observation of the Chinese consumer behaviors in the Dior's retail store in Venice underline some aspects should be analyzed and considered in facing the Chinese consumer going global. First of all the buying behavior is strictly influenced by the "recipe" the shopper has prepared before leaving the country and that has been given by the friends and relatives he/she is buying for. So, the amount of decisions and choices taken inside the shop is far lower than usual, if compared with a non Chinese customer. Luxury goods companies should therefore advertise their brands and products in China in order to sell in European stores, even products that are not sold in China, but normally part of the European assortments. This is important for the new trend in Chinese consumers that desire to have products that are not normally available in their country, so they can appear socially different and more sophisticated. Together with this kind of products not sold in China, European shops should sell typically Chinese oriented products, as in the case of Chinese New Year tradition, that are totally devoted to globetrotter Chinese travelers and not to European customers.

A second aspect concerns the tourist behavior of the luxury goods shoppers. As we discover during the research and observation period the most number of Chinese customers are traveling in groups, this condition should be taken in account when defining the sales strategies of the retail store in the touristic cities of Europe. It means that the luxury brand companies should develop agreements with the incoming tour operators in order to include their stores in the visit program of the travel. This is positive both for the luxury brands, increasing their sales opportunities, and for the tour operators, because the Chinese tourists are really interested in shopping. Nevertheless this strategy represents a new challenge for the luxury brands, because they are not used to such a relationship, normally considered not consistent with the image and the prestige of the brand. Actually, the agreement, even informal, with the tour operators are normally promoted by medium-low cost local ethnic stores. Obviously the relationship between tour operators and luxury brands should lead to a rich service and exclusive offer, coherently with the image of the brand.

A third point regards the time management in the buying and sales behavior. The customers don't manage their personal time because they are traveling in group. It means that when the group leader announces that the time is passed everyone leaves the store immediately, because they have a strict timetable. In welcoming the Chinese customers all the salespersons should know precisely the time the shoppers can spend in shopping, because they are the only ones that could manage the available time, 
avoiding to be unable to close the sale in time. In fact many (96) observations showed that the customer dropped down the product he/she was buying because of the end of time. So the time management should become a new important skill of the salesperson in luxury sales.

A fourth aspect concerns the country of origin perception. Being the Chinese consumer not completely acquainted about brands, country of origin, and made-in differences, the question should be explained clearly to the customers and not considered as given, as in case of an European customer. A strong motivation for the purchase in Europe by the Chinese consumers is the reputation of authenticity of the products, that they consider more reliable than the ones available in China. This is obviously a perception due to the story of the Chinese market. However it should be considered in order to enforce the value of the purchase in European retail stores, emphasizing the information on the country of origin.

The fifth point is connected with the customer service. As the observations illustrate, salespersons devoted to Chinese customers must speak Chinese language, moreover they should be Chinese in order to facilitate the relationship and understand the buying culture of the customers. Also in the point of sales a communication in Chinese should be displayed, together with the local language, and the customer service should be defined considering the Chinese standards and expectations (for example shipment to Hong Kong in order to avoid import taxes).

So we can consider as confirmed both $\mathrm{H} 1$ and $\mathrm{H} 2$. The retail stores of the luxury brands should take a double face image, both Chinese and European, Chinese in the customer service, European in atmosphere. As you can understand this is a difficult choice to be developed, because following this approach the stores should manage a double totally different strategy if the customer is Chinese or not, considering service, time management, payments (due to tax refund) and product presentation. If at the same time there are the two profiles of customers in the shop, it should be reasonably expected every day, the shop attendants should manage a totally different set of expectations that are frequently not easy combinable.

This research contributes to the retail strategy theory in luxury products regards the strong difference compared to the traditional theoretical approach to the luxury retail customer service. As a matter of facts the Chinese luxury shoppers, which represent more than $80 \%$ of the sales in European stores, change the rules of the game. The traditional customer service theory, based on long and careful relationship, exclusive spaces and atmospheres, timeless and experiential experiences inside the point of sales are not fitting with the needs of Chinese luxury shoppers. The idea of luxury flagship store must be reconsidered and innovate, coping with the paradox represented by traditional European customer desires and new Chinese ones: the same location for two totally different approaches.

\section{LIMITATIONS AND CONCLUSION}

The research process was heavily limited by the particular situation of a luxury retail store, due to the specific customer profiles and sales service. In fact was impossible to approach directly the customers, both inside and outside the store, because luxury 
goods consumers don't want to be interviewed or evidently observed while they buy. So the research approach should be totally indirect, similar to a mystery research.

Moreover, just because of the aspect described above, we could only include one luxury brand in our sample definition, while a comparison between more brands seems to be more correct and fruitful, even considering a different country of origin. For the same reason should be interesting to include in the sample also multiple store location, not only in a single country, but in different European countries, mainly Italian and French.

Nevertheless, despite the event limitations this research disclosed an additional aspect in the luxury goods buying behavior that is strictly connected with the globalization of the Chinese customer, influencing the sales strategy of western companies not only in China but also in their domestic markets.

\section{REFERENCES}

Amatulli, C., Guido, G. (2011) "Determinants of purchasing intention for fashion luxury goods in the Italian market. A laddering approach", Journal of Fashion Marketing and Management, vol.15, n. 1.

Arrigo, E. (2015) "The role of the flagship store location in luxury branding. An international exploratory study", International Journal of Retail \& Distribution Management, Vol. 43 Issue 6.

Bain \& Company Consulting Group, Lens on the Worldwide Luxury Consumer, January 2016.

Baruca, A., Zolfagharian, M. (2013) "Cross-border shopping: Mexican shoppers in the US and American shoppers in Mexico" International Journal of Consumer Studies, Jul, Vol. 37 Issue 4.

Bian, Q., Forsythe, S., (2011) "Purchase intention for luxury brands: A cross cultural comparison", Journal of Business Research, 65, Elsevier, October.

Chen, J., Kim, S. (2013) "A Comparison of Chinese Consumers' Intentions to Purchase Luxury Fashion Brands for Self-Use and for Gifts", Journal of International Consumer Marketing. Jan/Feb, Vol. 25, Issue 1.

Choi, M.J., Heo, C.Y. Law, R. (2016) "Developing a Typology of Chinese Shopping Tourists: An Application of the Schwartz Model of Universal Human Values", Journal of Travel \& Tourism Marketing, Feb-Mar, Vol. 33 Issue 2.

Dmitrovic, T., Vida, I. (2007) "An examination of cross-border shopping behaviour in South-East Europe", European Journal of Marketing, Vol. 41 Issue 3/4.

Gilbride, T.J., Inman, J. J., Melville Stilley, K. (2015), "The Role of Within-Trip Dynamics in Unplanned Versus Planned Purchase Behavior", Journal of Marketing, May, Vol. 79 Issue 3.

Gillison, S., Reynolds, K. (2016) "Shopping for yourself versus shopping for someone else", Journal of Consumer Marketing, Vol. 33 Issue 4.

Godey, B., et al, (2013) "Brand and country-of-origin effect on consumers' decision to purchase luxury products", Journal of Product \& Brand Management, Vol. 22, N. 3. 
Guo, C., Vasquez-Parraga, A. Z., Wang, Y. (2006) "An exploratory study of motives for Mexican nationals to shop in the US: More than meets the eye", Journal of Retailing \& Consumer Services, Sep, Vol. 13 Issue 5.

Guo, C., Wang, Y.J. (2009) "A study of cross-border outshopping determinants: mediating effect of outshopping enjoyment", International Journal of Consumer Studies, Nov, Vol. 33 Issue 6.

Guoxin, L., Guofeng, L., Zaphaniah, K., (2011) "Luxury fashion brand consumers in China: Perceived value, fashion lifestyle, and willingness to pay", Journal of Business Research, October.

Henderson, J.C., Chee, L., Mun, C. N., Lee, C.(2011) "Shopping, tourism and retailing in Singapore", Managing Leisure, Jan, Vol. 16 Issue 1.

Hernandez, M. D., Vicdan, H. (2014) "Rethinking flow: qualitative insights from Mexican cross-border shopping", International Review of Retail, Distribution \& Consumer Research, Jul, Vol. 24 Issue 3.

Leal, A., López-Laborda, J., Rodrigo, F. (2010) "Cross-Border Shopping: A Survey", International Advances in Economic Research, May, Vol. 16 Issue 2.

Li, W-K., Wong, N. (1998) "Culture and Consumption: Luxury and Leisure Consumption in Asia", Advances in Consumer Research, Vol. 25 Issue 1.

Manlow, V., Nobbs, K. (2013) "Form and function of luxury flagships. An international exploratory study of the meaning of the flagship store for managers and customers", Journal of Fashion Marketing \& Management, Vol. 17 Issue 1.

McKinsey Insight China (2013), Luxury Consumer Studies 2010-2012. McKinsey.

Minghetti, V., Celotto, E. (2014) "Measuring Quality of Information Services: Combining Mystery Shopping and Customer Satisfaction Research to Assess the Performance of Tourist Offices", Journal of Travel Research, Sep, Vol. 53 Issue 5.

Park, K-S., Reisinger, Y. (2009) "Cultural Differences in Shopping for Luxury Goods: Western, Asian, and Hispanic Tourists", Journal of Travel \& Tourism Marketing, Dec, Vol. 26 Issue 8.

Park, K-S., Reisinger, Y., Noh, E-H. (2010 ) "Luxury shopping in tourism", International Journal of Tourism Research, Mar/Apr, Vol. 12 Issue 2.

Piron, F. (2001) "International Retail Leakages: Singaporeans Outshopping in Malaysia", Singapore Management Review, 1st Half, Vol. 23 Issue 1.

Piron, F. (2002), "International outshopping and ethnocentrism European" Journal of Marketing., Vol. 36 Issue $1 / 2$.

Reimers, V. Chao, F. (2014) "The role of convenience in a recreational shopping trip", European Journal of Marketing, Vol. 48 Issue 11/12.

Roland Berger Strategy Consultants (2014) Travel retail in Asia Report, What's the changing face of Chinese shopping abroad.

Siu, N. Y-M.,Kwan, H.Y., Zeng, C.Y. (2016) "The role of brand equity and face saving in Chinese luxury consumption", Journal of Consumer Marketing, Vol. 33 Issue 4.

Solca, L., Bertini, P., Fan, H. (2013) All about China, Exane BNP Parisbas Report.

Spierings, B., van der Velde, M., (2013) "Cross-Border Differences and Unfamiliarity: Shopping Mobility in the Dutch-German Rhine-Waal Euroregion”, European Planning Studies, Jan, Vol. 21 Issue 1.

Sullivan, P., Bonn, M.A., Bhardwaj, V., DuPont, A. (2012) "Mexican national crossborder shopping: Exploration of retail tourism", Journal of Retailing \& Consumer Services, Nov, Vol. 19 Issue 6. 
Susilo, Y.O., Hanks, N., Ullah, M (2013) "An exploration of shoppers travel mode choice in visiting convenience stores in the UK", Transportation Planning \& Technology, Vol. 36 Issue 8.

Tisovski, M. (2014) "Profiling Customer Types in Luxury Retail Setting", Central European Business Review, vol. 3, n. 4.

van der Wiele, T., Hesselink, M., van Iwaarden, J (2005) "Mystery shopping: A tool to develop insight into customer service provision", Total Quality Management \& Business Excellence, Jun, Vol. 16 Issue 4.

Vescovi, T., Checchinato, F., Disegna M. (2013) "Does country of origin affect brand associations? The case of Italian brands in China". Journal of Global Scholars of Marketing Science, vol. 23,

Wang, D. (2004) "Hong Kongers' cross-border consumption and shopping in Shenzhen: patterns and motivations", Journal of Retailing \& Consumer Services, May, Vol. 11 Issue 3.

Wang, Y. J., Doss, S. K., Guo, C., Li, W. (2010) "An investigation of Chinese consumers' outshopping motives from a culture perspective", International Journal of Retail \& Distribution Management, Vol. 38 Issue 6.

Wang, Y., Sun, S., Song, Y. (2011) "Chinese Luxury Consumers: Motivation, Attitude and Behavior", Journal of Promotion Management. Jul-Sep, Vol. 17 Issue 3.

Wilson, A. M. (2001) "Mystery Shopping: Using Deception to Measure Service Performance", Psychology \& Marketing, Jul, Vol. 18 Issue 7.

Wong, I.A., Lam, Iok Keng,V. (2016) "A Multilevel Investigation of the Role of Retail Stores in Cross-Border Shopping", Journal of Travel \& Tourism Marketing, Aug-Sep, Vol. 33 Issue 6.

Yavas, U., Abdul-Gader, A. (1991) "Trans-border outshopping: an Arabian Gulf study", International Review of Retail, Distribution \& Consumer Research, Jul, Vol. 1 Issue 4.

Young J.W., Doss S.K., Chiquan Guo., Wenjing Li (2010) "An investigation of Chinese consumers' outshopping motives from a culture perspective", International Journal of Retail and Distribution Management, Vol. 38, n. 6.

Zaidan, E. A. (2016) "Tourism shopping and new urban entertainment", Journal of Vacation Marketing, Jan, Vol. 22 Issue 1.

Zhan, L., He, Y. (2012) "Understanding luxury consumption in China: Consumer perceptions of best known brands", Journal of Business Research, Volume 65, Issue 10, October. 